\title{
GOMMENTARY
}

\section{Something Old, Something New: The Syndemic of Racism and COVID-19 and Its Implications for Medical Education}

\author{
Joshua Freeman, MD
}

(Fam Med. 2020;52(9):623-5.)

doi: 10.22454/FamMed.2020.140670

$\mathbf{T}$ wo seismic issues, racism and COVID-19, have engaged the United States in the last several months, acting together to create what is known as a syndemic ${ }^{1-}$ a set of linked health problems that interact synergistically to contribute to excess burden of disease in a population-that seriously impacts the health of all of us. Racism is old; it has always been a defining characteristic of our country. Triggered by episodes of police killing of people of color, particularly the murder of George Floyd, we have seen extraordinarily broad discussion about it. The Black Lives Matter movement reminds us of the history of racism in the United States, from slavery, to lynchings and Jim Crow segregation, to mass incarceration (the "New Jim Crow" inequity that begins at birth for every Black child as a result of the social constructs of race and racism.

COVID-19 is new, the biggest world-wide pandemic at least since the 1918 influenza pandemic. While it started in China, the United States has become the world epicenter of the disease with the most cases and deaths (over 5 million cases, more than a quarter of all those in the world, and nearly 200,000 deaths as of this writing). ${ }^{3}$ As everywhere, the disease has hit the poorest, sickest, and most vulnerable communities the hardest; in the United States that has meant minorities, in whom the infection rate is at least twice that of Whites. ${ }^{4}$ The causal virus SARS-CoV-2 does not discriminate, but the society in which it occurs does. People of color, and especially

African Americans, have far higher rates of most chronic diseases, which makes them more vulnerable both to becoming infected and for worse outcomes when infected. Even before COVID, African Americans had mortality rates much higher than those of Whites, particularly for the most common chronic diseases: diabetes, cancer, heart disease, and stroke. ${ }^{5,6}$

People of color are not more vulnerable, and do not have more chronic disease as a result of genetics or biology. ${ }^{7}$ The genetic variation among people of the same race is at least 10 times that between races. ${ }^{8,9}$ The true causes of population health disparity are collectively known as the social determinants of health (SDH): factors such as adequate housing, food, income, and education, to provide the basis for a reasonably healthy life. In the United States, racism is a major SDH. People of color are overrepresented at lower socioeconomic levels; Black families have an average wealth of less than $10 \%$ of that of White families. ${ }^{10}$ Chronic stress is a critical outcome of the SDH, whether from worrying about whether you can feed or house your family, or from fear that you, or your spouse, or your children, may be killed or jailed at any time, when simply walking down the street or driving your car can put you in danger. ${ }^{11}$ Racism has placed people of color, over generations, in the situation of

From the Department of Family and Community Medicine, University of Arizona College of Medicine, Tucson, AZ; and the University of Kansas School of Medicine, Department of Family Medicine. 
having worse SDH. This makes them chronically less healthy, more likely to have chronic disease, less likely to have adequate health insurance, and more susceptible to the effects of a pandemic such as COVID-19. It is this impact that creates and perpetuates the current syndemic.

While SDH have a huge impact on the presence and severity of disease, medical outcomes are often tied to access to treatments impacted by the quality of a person's insurance. A universal single-payer health insurance system would obviate that disparity, because everyone would be covered, and when everyone is in the same system everyone has access to the same options for diagnosis and treatment.

Medical education also occurs within this racist reality. LaShrya Nolen, a medical student writing in the New England Journal of Medicine, uses the fact that early Lyme disease only appears as the characteristic bullseye lesion of erythema migrans on white skin to suggest that the failure to recognize it may cause later diagnosis and a greater likelihood of advanced Lyme disease in people of color. More importantly, she makes the general point that "normal" is consistently assumed to be "White". ${ }^{12}$ Recently, the practice of adjusting estimated glomerular filtration rate levels for African Americans has been questioned, and a number of major hospitals have abandoned it. ${ }^{13}$ Several recent articles address the continuous experience of racist and derogatory comments from physicians and patients alike, the presumption of a greater likelihood of self-destructive behaviors by members of minority groups, and the degree to which such comments are often not only unchallenged but assumed to be normative. ${ }^{14-18}$

One paper in particular, from a group of medical students, provides an outstanding review of both the deep roots of racism in medicine and the current practice in medical education of using race to create shortcuts and heuristics that are frequently wrong, as well as racist. The authors succinctly state that "The imprecise use of race-a social construct-as a proxy for pathology in medical education is a vestige of institutionalized racism," and make a number of suggestions for amelioration. ${ }^{19}$ Additional curricular strategies for addressing racism in medical education can also be found in the Family Medicine special issue from January $2019 . .^{20}$

For medical education to successfully address racism, it must start by examining every area in which teaching and learning occur, from basic science lectures to clinical rounds to the informal or hidden curriculum. Seminars addressing unconscious bias are good, but we must have zero tolerance for conscious bias, casual racism, and comments about people and false assumptions about populations, just as we should for sexual harassment. We must empower those who challenge such statements or behaviors, and protect them, even when it is the most junior student challenging the most senior attending. Why do we teach students to open their presentations with race: "The patient is a 53-year-old Black male"? In general, most references to race are inherently racist. They certainly are never "just a joke."

The performance of our medical schools and academic health centers should be evaluated on how they actually perform in four key areas:

1. Diversity: Does the school produce a health workforce that looks more like America by enrolling and supporting a group of students that is truly diverse in ethnicity, gender, socioeconomic status, and geographic origin?

2. Social determinants of health: Does the school teach and carry out programs aimed at addressing the SDH? Does it require every patient presentation to address the SDH equally with the traditional medical content? Do students make home visits to understand first-hand the context of people's lives? How much student training occurs in community and primary care settings?

3. Disparities: Through its programs of education and community intervention, and its research agenda and practice, does the school explicitly work to reduce disparities in health care and health among populations? Do its graduates practice in specialties and areas of need, and thus help reduce health disparities?

4. Community engagement: Does the academic health center clearly identify the community it serves? Does it involve the community in determining the location of training, the kinds of programs it carries out, and in identifying the questions that need to be answered by research?

These changes are not going to happen easily, quickly, or without offending anyone. Indeed, it is quite possible that they will not happen, or not happen as broadly and deeply as they need to, if left to the same people who have 
been running the existing medical education system. They strike at the heart of our tacit assumptions of normal. But normal is not the same as adequate. To achieve health equity, and a healthy and safe society, we all need to take this on, students, faculty, and patients. We need to take it seriously, and take it to the limit.

CORRESPONDENCE: Address correspondence to Dr Joshua Freeman, jfreeman@kumc.edu.

\section{References}

1. Merrill S. Introducing Syndemics: A Critical Systems Approach to Public and Community Health. San Fracisco: Jossey-Bass; 2009: 304.

2. Alexander M. The New Jim Crow: Mass Incarceration in the Age of Colorblindness. New York: New Press, 2012.

3. Gutierrez P, Clark S. Covid-19 world map: which countries have the most COVID-19 cases and deaths? The Guardian. August 10, 2020. https://www.theguardian.com/world/2020/ aug/10/coronavirus-world-map-which-countries-have-themost-covid-19-cases-and-deaths. Accessed September 1, 2020.

4. Hammonds EM, Reverby SM. Economic reforms might be the best health-care reforms. Washington Post. August 3, 2020. https://www.washingtonpost.com/outlook/2020/08/03/ economic-reforms-might-be-best-health-care-reforms/. Accessed September 1, 2020.

5. Woolf S, Johnson RE, Fryer GE, Rust G, Satcher D. The health impact of resolving racial disparities: an analysis of US mortality data. Am J Pub Health. 2004;94:2078-2081

6. Wezerek G. Racism's Hidden Toll: In America, how long you live depends on the color of your skin. New York Times. August 11, 2020. https://www.nytimes.com/interactive/2020/08/11/opinion/us-coronavirus-black-mortality. html. Accessed September 1, 2020

7. Moscou S, Anderson MR, Kaplan JB, Valencia L. Validity of racial/ethnic classifications in medical records data: an exploratory study. Am J Public Health. 2003;93(7):1084 1086

8. Lewontin R. Biology as Ideology: The Doctrine of DNA New York: Harper-Collins Publishers; 1992.

9. Lewontin R, Rose S, Kamin L. Not in Our Genes: Biology, Ideology, and Human Nature. New York: Pantheon Books; 1984.
10. Hansen S. Here's What The Racial Wealth Gap In America Looks Like Today. Forbes. June 5, 2020. https://www.forbes. com/sites/sarahhansen/2020/06/05/heres-what-the-racialwealth-gap-in-america-looks-like-today/\#5f0667c0164c. Accessed September 1, 2020.

11. Derrick CB. Sirens: 4 decades of harassment by the police. Guernica. July 27, 2020. https://www.guernicamag.com/ sirens/. Accessed September 1, 2020

12. Nolen L. How Medical Education Is Missing the Bull'seye. N Engl J Med. 2020;382(26):2489-2491. doi:10.1056/ NEJMp1915891

13. Zoler ML. Dropping Race-Based eGFR Adjustment Gains Traction in US. Medscape. July 6, 2020. https://www.medscape.com/viewarticle/933418. Accessed September 1, 2020.

14. Tweedy D. Medical Schools Have Historically Been Wrong on Race. New York Times. July 27, 2020. https://www. nytimes.com/2020/07/27/opinion/sunday/coronavirus-medicine-blackness.html. Accessed September 1, 2020.

15. Goldberg E. For Doctors of Color, Microaggressions Are All Too Familiar. New York Times. August 11, 2020. https:// www.nytimes.com/2020/08/11/health/microaggressionmedicine-doctors.html. Accessed September 1, 2020.

16. Gordon M. Racism, Hazing And Other Abuse Taints Medical Training, Students Say, Democracy Now! NPR. June 16,2020. https://www.npr.org/sections/healthshots/2020/06/16/876279025/racism-hazing-and-otherabuse-taints-medical-training-students-say. Accessed September 1, 2020.

17. Okwerekwu JA, What happened when I talked about what others ignore - racism in medicine. StatNews. April 27, 2016. https://www.statnews.com/2016/04/27/racismmedicine-lessons/. Accessed September 1, 2020.

18. Okwereku JA, The patient called me 'colored girl.' The senior doctor training me said nothing. StatNews. April 16, 2016. https://www.statnews.com/2016/04/11/racismmedical-education/. Accessed September 1, 2020.

19. Nieblas-Bedolla E, Christophers, B, Nkinsi NT, Schumann PD, Stein E, Changing How Race Is Portrayed in Medical Education. Acad Med. May 5, 2020. Published Ahead of Print.

20. Society of Teachers of Family Medicine. Family Medicine Journal. 2019. Volume 51, Issue 1. 